\title{
How To Use the Checklist
}

Manuscripts and related material in the Jonas Collection are filed by box and folder number. In turn these boxes and folders are divided into groups (I-V) and sections $(\mathrm{a}-\mathrm{g})$. The general arrangement is apparent in the table of contents, the major manuscript sections being Group I, Schenker archive; Group II, Jonas papers; and Group III, Violin papers.

Manuscripts in the Jonas collection for the most part were written on acidcontent paper, now grown brittle after nearly a century. Frequent handling of the material results in damage and in some loss of text. For this reason the original manuscripts will be protected, microfilmed, and enclosed in mylar. Access will primarily be to the microfilm (which will also be keyed to box and folder numbers) with the originals available to be consulted when necessary for verification.

Details of arrangement in each section are given below:

Tagebücher (I a). Pagination in Schenker's Diaries is very irregular and the collation attempts to describe the actual sequence of numbered leaves. Series $A$ is the basic diary; $B$ and $C$ are parallel series with overlapping dates covering shorter periods.

The Tagebücher are not indexed except for the small notebook compiled by the Schenkers (Box 4 f.9) covering names and subjects up to Sept. 23, 1912.*

Correspondence (I b, c; II a, b; III a, b; IV). Letters or other documents where Schenker is the writer or recipient are all found in Group I. Next in priority are letters with Jonas as writer or recipient (Group II) and third, letters with Violin as writer or recipient (Group III). Thus, if the Schenkers are recipients, all such letters, even if from Jonas or Violin, are found in Group I. Listed in Group IV are a small number of letters in which none of the three principals is involved as correspondent.

Correspondence is identified as autograph (A) or typed (T), whether a letter (L), postcard (P), or note (N), and whether signed (S) or unsigned (U). For each correspondent file, letters are arranged in the following order:
ALS
Autograph Letter Signed
ALU
Autograph Letter Unsigned
APS
Autograph Postcard Signed
APU
Autograph Postcard Unsigned
ANS
Autograph Note Signed
ANU Autograph Note Unsigned

\footnotetext{
* For a summary and excerpts from the diaries and correspondence, see Hellmut Federhofer, Heinrich Schenker nach Tagebüchern und Briefen in der Oswald Jonas Memorial Collection. Hildesheim: Georg Olms, 1985 [Special Collections ML423 S33F45 1985]
} 


$\begin{array}{llll}\text { TLS } & \text { Typed Letter Signed } & \text { TLU } & \text { Typed Letter Unsigned } \\ \text { TPS } & \text { Typed Postcard Signed } & \text { TPU } & \text { Typed Postcard Unsigned } \\ \text { TNS } & \text { Typed Note Signed } & \text { TNU } & \text { Typed Note Unsigned }\end{array}$

Correspondence files are arranged alphabetically by recipient (e.g., letters from Schenker, I b) or by writer (letters to Schenker, I c). Within each folder, letters are arranged by type (such as ALS) and within each type chronologically, undated letters first, followed by the earliest date. Inclusive dates and number of letters of each type are given but not pagination or other bibliographic data. Documents other than letters or cards are listed at the end. In the following entry listing letters from Furtwängler to Schenker (I c), folder 16 of Box 11 contains six undated autograph letters signed, eleven autograph letters signed and dated between 1919 and 1934 (with one signature missing), two autograph postcards signed and dated 1923, and five typed letters signed and dated between 1932 and 1937, (Letters after 1935 were addressed to Jeanette Schenker):

$11 \mathrm{f} .16$

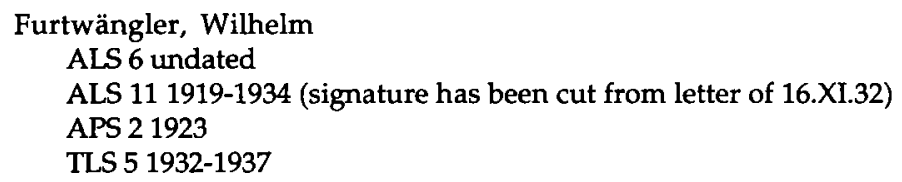

Dates enclosed in square brackets have been derived from other evidence than the writer's own dating. Original envelopes are included when found.

Letterheads provide clues to the writer's connections and are listed in parentheses after the signatory's name. Thus in I c:

12 f.49

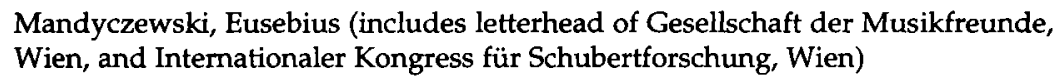

indicates that Mandyczewski wrote at least one letter on the letterhead of each of the organizations listed. The parenthetical qualifier "(with letterhead of...)" indicates that all of the correspondence includes the letterhead. Neither qualifier is intended to describe the subject of the correspondence.

Schenker's Critical and Analytical Works (I d). In this group, largely Jonas's arrangement, are listed many of Schenker's published critical works, comprising original manuscripts as prepared for the printer, some page proofs, and printed editions with corrections. Included are Jonas's editions of Schenker's work. The material is divided into six subsections (with some overlap):

Box 16-17. Schenker's critical writings arranged by composer; largely Beethoven, excluding the complete edition of the piano sonatas listed in I $\mathrm{f}$.

Box 18-19. Schenker's major works on theory and analysis arranged by date. Includes some Jonas editions, e.g., his English edition of the Harmonielehre.

Box 20. Essays and reviews by Schenker as first published in the periodical press. Arranged by periodical title and then by date. Few original issues; largely Jonas transcripts and photocopies.

Box 21 f.1-6. Other writings by Schenker. Minor works; non-musical writings. 
Box 21 f. 7-21. Notes and drafts for Die Kunst des Vortrags and other projects.

Box 21 f.22-25. Essays and announcements concerning Schenker's works.

Schenker As Composer (I e). Manuscripts in Schenker's hand, manuscripts in a copyist's hand, and published editions. There are seven subsections:

Box 22 f.1-13. Vocal music with opus numbers (arranged by opus).

Box 22 f.14-36. Vocal music without opus numbers (arranged by title).

Box 23 f.1-7. Instrumental music: solo piano works.

Box 23 f.8-16. Works for piano 4 hands (includes orchestral versions of Syrische Tänze by Violin [1922-] not part of the Schenker Nachlass).

Box 23 f.17-24. Trios.

Box 23 f.25-28. String quartets.

Box 23 f.29-30. Other instrumental works and sketches.

Schenker's Research and Teaching (I f). Box 24-34. Arranged by composer; under composer by opus number. Included are published editions by Schenker (and revisions by Jonas), published editions by others with autograph annotations by Schenker, manuscript copies by others, performance copies, analytical studies and related material. The extensive Beethoven section (Box 26-30) includes annotated copies and corrected page proofs of Schenker's edition of the complete piano sonatas. Following the composer section are three smaller sections:

Box 33 f.4-6. Other research and teaching materials. Analytical studies by Schenker and others with musical examples for "Lehre vom Vortrag" (prepared by Jonas).

Box 34 f.1-14. Articles and publications of others. A small collection of clippings and excerpts, found in the Schenker Nachlass.

Box 34 f.15-17. Miscellany. A few studies for Kontrapunkt; student exercises; periodicals, including annotated pages of Radio Wien.

Schenker Biographical Materials (I g). Box 35. Personal documents, business and financial records.

Jonas Correspondence (II a, b). Box 36. For arrangement, see under Correspondence $(\mathrm{I} b, \mathrm{c})$ etc.

Critical Works of Oswald Jonas (II c). Box 37-38. Largely published material, but includes final manuscripts, notes and drafts, arranged alphabetically by title, with Jonas's book reviews at the end.

Jonas's Research and Teaching (II d). Box 39-68. Arranged by composer and opus number. Under "Schenker, Heinrich" are arranged materials collected by Jonas for his publications:

Box 57. Writings by Jonas about Schenker, including a draft outline for "Lehre vom Vortrag."

Box 58. Publications by others about Schenker, largely journal articles, including a few items since 1978. Box 59. Excerpts compiled by Jonas for proposed Schenker biography. Largely typed transcripts from correspondence and the Tagebücher. 
Following the composer section are three subgroups:

Box 61-62 f.4. Miscellaneous Jonas lecture notes, largely unfinished drafts or outlines.

Box 62 f.5-63 f.8. Collected bibliographic and historical excerpts, largely clipping files and pamphlets. Box 64-68. Slides and microfilm collection.

Jonas Biographical Materials (II e). Box 69. Personal documents, lists of scholars, etc.

Moriz Violin Papers (III a, b, c). Box 70. Arranged like Groups I and II.

Box 70 f.1-48. Correspondence. For arrangement, see under Correspondence (I b, $c$ ), etc.

Box 70 f.49-73. Works by and about Moriz Violin; biographical materials, performance reviews, etc.; letters of recommendation for Violin.

Other Correspondence (IV). Box 71. Arranged by writer. See Correspondence (I b, c), etc.

Photographs and Other Portraits (V). Box 72-73. Arranged by subject; oversize items also listed in Box 72 but physically located in Box 73 .

First and Early Editions (VI). Not physically located with the Jonas Memorial Collection but catalogued and shelved in the book stacks of the Special Collections Department.

Appendix: List of Acquisitions Since 1978. Contains information about new items added since Jonas's death.

Index. Locates all personal names and corporate names listed in the Checklist; also indexes (selectively) titles of musical works, titles of books reviewed by Schenker, and periodical titles. Expanded entries for Jonas, Schenker, and Violin index works by the three authors.

\section{A NOTE ON NAMES AND TITLES CITED IN CHECKLIST ENTRIES}

Names of institutions and titles of works cited are normally given in the language of original publication. Places of publication or places where institutions are located are given in the form used in the language of origin, in this case often in the German form.

Titles of musical works are usually given in the language of the composer, unless much better known by the English title. Conventional titles of musical works are given in roman type; titles of published works appear in italics, and manuscript titles are given within quotation marks.

Most of the Checklist copy was prepared before the destruction of the Berlin Wall and the reunification of Germany, hence the designations Berlin [East] and [West] in entries. These descriptions have been allowed to stand as geographic terms; they may also help to identify libraries as they existed in Jonas's post-war Germany. 